\section{Thrombocytopenia in hypothermia: a common but poorly recognised complication}

Thrombocytopenia is a poorly recognised complication of accidental hypothermia, although it has been observed during the deep hypothermia used in cardiac surgery. ${ }^{1}$ Villalolobos et al showed that sequestration of platelets in the hepatic and splenic circulation is the main mechanism for the thrombocytopenia and that most of the platelets return to the circulation on rewarming. ${ }^{2}$ The thrombocytopenia may also reflect other disorders including disseminated intravascular coagulation, ${ }^{3}$ and hypothermia may have a direct effect on the bone marrow. ${ }^{4}$ We report two cases of thrombocytopenia as a complication of hypothermia in the elderly.

\section{Case reports}

CASE 1

An 82 year old woman was found collapsed at home. On admission she was unconscious and hypothermic with a rectal temperature of $27^{\circ} \mathrm{C}$ Pulse was 60 beats/minute regular and blood pressure $120 / 90 \mathrm{~mm} \mathrm{Hg}$. In the chest there were widespread coarse crackles. Abdominal and neurological examinations were normal. She had a considerable epistaxis and bruised easily after venesection. She was not receiving any drugs.

Investigations showed a haemoglobin concentration of $13 \cdot 2 \mathrm{~g} / \mathrm{dl}$, white cell count $5.8 \times 10^{9} / 1$, and platelet count $33 \times 10^{9} / 1$. Serum potassium concentration was $5.7 \mathrm{mmol}(\mathrm{mEq}) / 1$, sodium $145 \mathrm{mmol}(\mathrm{mEq}) / 1$, urea $10 \cdot 4$ $\mathrm{mmol} / 1(62 \mathrm{mg} / 100 \mathrm{ml})$, creatinine $130 \mu \mathrm{mol} / 1(1.5 \mathrm{mg} / 100 \mathrm{ml})$, and blood glucose $5 \cdot 2 \mathrm{mmol} / \mathrm{l}(94 \mathrm{mg} / 100 \mathrm{ml}$ ). Arterial blood gas tensions (on air) were: $\mathrm{pH} 7 \cdot 18$, carbon dioxide tension $6.3 \mathrm{kPa}(47 \mathrm{~mm} \mathrm{Hg})$, and oxygen tension $8.5 \mathrm{kPa}(64 \mathrm{~mm} \mathrm{Hg})$. Prothrombin time, kaolin cephalin clotting time, and thrombin time, fibrinogen concentration, results of thyroid function tests, and plasma cortisol concentration were all normal. A chest $x$ ray film showed consolidation of the right middle lobe. An electrocardiogram was normal.

On rewarming the platelet count rose to $230 \times 10^{9} / 1$ by the third day of admission. Her pneumonia resolved after treatment with cefuroxime and metronidazole.

\section{CASE 2}

An 83 year old woman was found unconscious in a cold room. On admission she was unrousable and her rectal temperature was $31.9^{\circ} \mathrm{C}$. She was in atrial fibrillation with blood pressure $140 / 95 \mathrm{~mm} \mathrm{Hg}$. Examination was otherwise normal. After venesection there was considerable bruising of both forearms. Investigation showed a haemoglobin concentration of $15.9 \mathrm{~g} / \mathrm{dl}$, white cell count $4.8 \times 10^{9} / \mathrm{l}$, and platelet count $62 \times 10^{9} / 1$. Electroyte concentrations were normal and blood glucose $3.7 \mathrm{mmol} / 1(67 \mathrm{mg}$ $100 \mathrm{ml})$. Results of coagulation screening and thyroid function tests, serum bilirubin concentration, and alkaline phosphatase activity were normal; but serum aspartate transaminase activity was $98 \mathrm{IU} / 1$.

With gradual rewarming and intravenous fluids her conscious level mproved over 12 hours. The platelet count rose to $249 \times 10^{9} / 1$ within one week.

\section{Comment}

Although thrombocytopenia is a recognised complication of infection, in case 1 the patient did not have septicaemia and the recovery of the platelet count corresponded more closely with rewarming than with the resolution of the pneumonia. Disseminated intravascular coagulation is reported to occur in accidental hypothermia and may explain the low platelet count, but in neither patient was there any evidence for this. A necropsy study of people who died of hypothermia, however, showed multiple haemorrhagic lesions and visceral infarctions, ${ }^{5}$ suggesting that many of these patients may have had thrombocytopenia associated with disseminated intravascular coagulation, so this condition may be commoner than has been clinically recognised.

Although the thrombocytopenia observed in hypothermia is rarely severe enough to cause a coagulation disturbance, the potential danger of bleeding remains. We suggest that a full clotting screen, including a platelet count and fibrinogen concentration, should be included in the initial management of these patients. The thrombocytopenia generally reverses when the patient is warmed, although in one study it worsened. ${ }^{3}$ Care is therefore advised in the rewarming process. More studies are needed to elucidate the pathogenetic mechanism for the disseminated intravascular coagulation in hypothermia. On balance it would seem logical to give prophylactic platelet transfusions to patients with platelet counts below $20 \times 10^{9} / 1$ or below $50 \times 10^{9} / 1$ if there is evidence of bleeding.

We thank Dr P Gower for his helpful comments.

1 Waddell WG, Fairby HB, Bigelow WG. Improved management of clinica hypothermia. Ann Surg 1957;146:542-4.

Villalolobos TH, Adelson E, Riley PA, Crosby WH. A cause of the thrombocytopenia and leucopenia that occurs in dogs during deep hypothermia. $\mathcal{F}$ Clin nvest $1958 ; 37: 1-7$

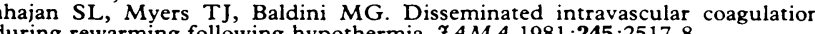
during rewarming following hypothermia. $\mathcal{F} A M A$ 1981;245:2517-8. hypoplasia and sideroblastic anaemia associated with hypothermia. Br f Haematol 1982;51:451-6.

5 Duguid H, Simpson RG, Stowers JM. Accidental hypothermia. Lancet 1961 ;i 1213.

(Accepted 26 March 1985)

Charing Cross Hospital, London W6

$P$ J EASTERBROOK, BSC, $M B$, house physician in medicine H P DAVIS, MRCPATH, lecturer in haematology

Correspondence to: Dr P Easterbrook, Department of Cardiology, John Radcliffe Hospital, Headington, Oxford.

\section{Mixed malarial infection due to Plasmodium falciparum and $P$ vivax}

We report on a man who developed both Plasmodium falciparum malaria resistant to chloroquine and $P$ vivax malaria that may have been resistant to primaquine.

\section{Case report}

A 26 year old man returned to Italy in September 1983 after having stayed for one month in a village in Uttar Pradesh, India. On returning home he had chills, vomiting, headache, muscle pains, and fever $\left(39 \cdot 5^{\circ} \mathrm{C}\right)$. Malaria parasites of unidentified species were found and $1500 \mathrm{mg}$ chloroquine base prescribed over three days. He became afebrile after two days. A week later the fever returned, and, without medical advice, he repeated the previous treatment. The fever resolved, but 20 days later he experienced evening fevers and night sweats.

On presentation he was afebrile, slightly jaundiced, and alert. The spleen was palpable $6 \mathrm{~cm}$ below the costal margin. A blood film was positive for $P$ falciparum, but the parasitaemia was not high; gametocytes could be seen Laboratory results showed leucopenia, slightly abnormal liver function, and modest increase in bilirubin concentration. He was prescribed quinine sulphate $650 \mathrm{mg}$ three times daily for 10 days, pyrimethamine $25 \mathrm{mg}$ twice daily for three days, and sulphadoxine $500 \mathrm{mg}$ twice daily for five days.

He did not travel to the tropics or endemic countries again and was well until March 1984, when during a visit to Atlanta, Georgia, United States, he once again experienced fever and headache. $P$ vivax malaria was diagnosed at the Centers for Disease Control. Chloroquine $600 \mathrm{mg}$ base for three days and then primaquine $15 \mathrm{mg}$ base daily for 14 days were prescribed. This primaquine schedule is currently recommended as the usual dosage for radical cure of $P$ vivax malaria. ${ }^{12}$ The patient, who had always shown good compliance, followed the recommended schedule.

A few days after his return to Italy in November symptoms of malaria recurred. The spleen was enlarged $7 \mathrm{~cm}$ below the costal margin, and a blood film was again positive for $P$ vivax. Chloroquine $1500 \mathrm{mg}$ base over three days and then primaquine $45 \mathrm{mg}$ base plus chloroquine $300 \mathrm{mg}$ base weekly for eight weeks were prescribed. ${ }^{3}$ We chose this intermittent high dose regimen to overcome drug resistance and to avoid possible gene linked drug induced haemolysis, although he had normal concentrations of glucose-6-phosphate dehydrogenase. ${ }^{1}$ After completing the course in January 1985 without any untoward side effects he remained in good health. Before we can state that this high dosage was effective against relapse, however, 12 months will have to elapse.

\section{Comment}

Strains of $P$ falciparum resistant to chloroquine are well known in Uttar Pradesh. Strains of $P$ vivax requiring a higher dose of primaquine for radical cure have been reported from the south west Pacific." In Tamil Nadu, India, $1.3 \%$ of over 8000 people infected with $P$ vivax relapsed after a course of primaquine lasting only five days. On the other hand, in some areas of Thailand $30 \%$ of patients relapsed after receiving $15 \mathrm{mg}$ daily for 14 days. ${ }^{4}$ Mixed infections with $P$ vivax and $P$ falciparum are quite common in India and have been reported 